\title{
Performance of Ornamental Plants in Different Media Compositions for Outdoor Vertical Gardening
}

\author{
Pattipaka Pavan Kumar*, Devi Singh and Urfi Fatmi \\ Department of Horticulture, SHUATS, Allahabad, India \\ *Corresponding author
}

\section{Keywords \\ Vertical garden, Media composition, Ornamental, Outdoor}

\section{Article Info}

Accepted: 17 September 2020 Available Online: 10 October 2020

\section{A B S T R A C T}

The present investigation was carried out about vertical garden as one of the most popular greenery systems in the modern era with 5 plants and 5 media compositions, at the Department of Horticulture, Sam Higginbottom University of Agriculture, Technology and Sciences, Prayagraj during Aug-2019 to Feb-2020 in Factorial Plot Design $(5 \times 5)$ with three replications. The data was recorded for 6 parameters. It is concluded from the results of the present investigation, that significant differences were observed for all the characters among the vertical garden plants. 5 vertical garden plants that are partial shade to shade loving were taken. 5 plants are $\mathrm{P}_{1}$ Spider Plant (Chlorophytum comosum), $\mathrm{P}_{2}$ Variegated screw pine (Pandanus spp.), $\mathrm{P}_{3}$ Sword fern (Nephrolepis exaltata), $\mathrm{P}_{4}$ Syngonium (Syngonium podophyllum), $\mathrm{P}_{5}$ Ipomea (Ipomeabatatus var. black heart) and 5 media compositions are $\mathbf{M}_{0^{-}}$Garden soil, $\mathbf{M}_{1}$-Perlite + Cocopeat + Sand(1:1:1), $\mathbf{M}_{2^{-}}$ Perlite + Cocopeat + Sand (1:1:2), $\mathbf{M}_{3}$ - Perlite + Cocopeat + Sand (1:2:1), $\mathbf{M}_{4}$ - Perlite + Cocopeat $+\operatorname{Sand}(2: 1: 1)$. Among these in the parameter of increasing in plant height, the maximum plant height was recorded at 180 days in $\mathrm{P}_{5}$ (Ipomea) $(8.2 \mathrm{~cm})$ and in the plant height, maximum range of media was recorded at 180 days in $\mathrm{M}_{4}$ (Perlite + Cocopeat + Sand $(2: 1: 1)(3 \mathrm{~cm})$. In the increase in number of leaves, the maximum number of leaves was recorded at 180 days in $\mathrm{P}_{5}$ (Ipomea) (4.1) and in number of leaves, the maximum range of media was recorded at 180 days in $\mathrm{M}_{0}$ (Garden soil) $(2.6 \mathrm{~cm})$. In the increase in plant spread, the maximum plant spread was recorded at 180 days in $\mathrm{P}_{3}$ (Fern) $(909.7 \mathrm{~cm})$ and in the plant spread, the maximum range of media was recorded at 180 days in $\mathrm{M}_{1}$ (Perlite + Cocopeat + Sand 1:1:1) $(652.9 \mathrm{~cm})$. In the leaf area, the maximum leaf area was recorded at 180 days in $\mathrm{P}_{3}$ (Fern) $\left(104.2 \mathrm{~cm}^{2}\right)$ and in the leaf area, the maximum range of media was recorded at 180 days in $M_{1}$ (Perlite + Cocopeat + Sand $\left.1: 1: 1\right)\left(53.3 \mathrm{~cm}^{2}\right)$. In the fresh vegetative mass, the maximum fresh vegetative mass was recorded at 180 days in $\mathrm{P}_{3}$ (Fern) (119.5g) and in the fresh vegetative mass, the maximum range of media was recorded at 180 days in $\mathrm{M}_{4}$ (Perlite + Cocopeat + Sand 2:1:1) (108g). In the root spread, the maximum root spread was recorded at 180 days in $\mathrm{P}_{3}(\mathrm{Fern})(21.7 \mathrm{~cm})$ and in the root spread, the maximum range of media was recorded at 180 days in $\mathrm{M}_{3}$ (Perlite + Cocopeat + Sand $1: 2: 1)(20.8 \mathrm{~cm})$. 


\section{Introduction}

The most important problems of the present day are urbanization and it causes many environmental problems. If the urban population increases, it enhances the structuring rate. The reason behind this is, the urban green spaces used for sightseeing, recreation, exercise, and relaxation areas are decreasing day by day. The green spaces have been disappeared at horizontal plane then the vertical gardens have been appeared in the picture. The vertical gardens will increase not only urban green areas but also have some specifications, such as sound and heat insulation, energy productivity. Air quality improvement. Heat island reduction, aesthetics occurrence, and positive contribution to human psychology (Ekren, 2017).

Human ecology says that humans are there in relationships with the environment, which has a history extending up to the times of the Garden of Eden (Waltke, 2016). Their ancestors also recognized essential roles of plants in providing pleasure, perfumes, peace, piety and glimpses of 'paradise. In contrast, the increasingly rapid growth of modern cities has been only over the last two hundred years (Bergs, 2002). Human species have continued to be biologically well adapted to nature, as we have encountered it over the period. They are still reliant on plants for everything they need - from food to shelter, supply of the lifegiving oxygen, and plants provide the sink for carbon dioxide.

The impact of urban development on natural ecosystems is severe due to habitat replacement and the amount of energy and materials required to sustaining the built environment. Green roofs provide a variety of services to the urban environment, including visual relief, accessible green space, storm water retention, reduced building energy consumption, and habitat provision for other organisms (Dunnett and Kingsbury, 2004). The use of plants on building surfaces has a long history, stretching back at least to the legendary Hanging Gardens of Babylon (Jeremy and Lundholm, 2006).

So far, there are roughly $1000+$ vertical gardens around the world. The largest Vertical Garden is in Paris. It has surface of $300 \mathrm{~m}$, is $30 \mathrm{~m}$ high, and can be implemented in any environment (light, wind, temperature, air humidity, either indoor or outdoor). Vertical garden is the solution to implement beautiful plant in any location where there are no horizontal places left for plants. Vertical surfaces in nature are mostly soilless, creating well drained growing locations (Sharma, 2015). The wall greenery improves visual and elegant aspects of indoor spaces. Adopting indoor living walls has many advantages (Choi, 2013; Köhler, 2008).

The most suitable plants for vertical garden are Spider plant, Ferns, Syngonium, Ipomea, Screw pine, Pothos, Dracaena, Crotons, Baby's tears, Philodendron, Geranium, Ribbon grass, Wandering jew, Purple heart, Bromeliads. Commonly, light weight media is preferable in vertical garden.

Spider Plant (Chlorophytum comosum), belonging to the family Asparagaceae. It is considered one of the most adaptable of houseplants and the easiest to grow. A mature plant will form tight rosettes of arching leaves with a profusion of hanging plantlets on long stems, up to three feet. Spider plants prefer bright light and tend toward scorching in direct sunlight. However, they will grow in conditions ranging from semi-shady to partial direct sun.

Variegated screw pine (pandanus spp.) family pandanaceae. A common name of screw pine comes from the spirally arranged leaves 
(screw-like spiral around the stem) and the pineapple like fruit which also resembles a large pine cone. 'Veitchii' (synonymous with and sometimes called Pandanus veitchii) is a variegated cultivar which contains features of spiny, pale green leaves with striking white margins. Some experts maintain that Pandanus veitchii is a species native to Madagascar. Other experts list this plant as a cultivar of Pandanus tectorius. It grows in average, medium moisture, well-drained soils in full sun to part shade. It likes warm, humid conditions. Garden sites that receive full, allday sun to partial afternoon shade make the best planting spots for pandans.

Nephrolepis exaltata, known as the Sword fern or Boston fern, is a species of fern in the family Nephrolepidaceae native to tropical regions throughout the world. An evergreen perennial herbaceous plant, the pinnae are generally deltoid, as seen in the adjacent picture. The pinnate vein pattern is also visible on these highly compound leaves. The edges appear slightly serrate. The plant can grow both terrestrially and as an epiphyte, linear to lanceolate and glandular. The rachis bears monochrome sprout soups.

Syngonium (Syngonium podophyllum), of family Araceae should be allowed to dry out between watering. Although the plant enjoys some moisture, it should not be kept too wet, which may lead to root rot. Leaves are generally green in color but there are many varieties that include variegated leaves of differing shades. The heavily variegated varieties require bright, filtered light. Average light is the norm for solid green varieties or those with less variegation. Keep it away from direct sunlight, as this will cause the arrowhead plant to burn or bleach. The arrowhead plant will tolerate low light levels on occasion. Ipomea (Ipomea black), belongs to family Convolvulaceae is an ornamental warm-season annual plant grown for its attractive leaves and vining habit. The foliage lends a tropical feel to the garden and comes in a range of colors and varying forms. Thrives in full to partial sun, plants should be moderately moist, watering once a week, or more during hot spells. Do not overwater or allow plants to dry out.

Potting media for these vertical gardens should be weightless, good porosity and neutral $\mathrm{pH}$, high nutrient holding capacity, high water holding capacity. Coco peat, perlite, sphagnum moss, vermiculite, vermicompost, and leaf molds, shredded bark are the common media combinations used. Water management is essential for the survival and growth of crops and is better achieved in limited soil volumes such as in containerized plants. The choice of a suitable medium depends on availability, cost, requirements of the plants, ability to grow the best plants and give greatest return on the investment.

Cocopeat or coir is a by-product from the processing of coconut husks and has absolutely no nutrition in it, but has excellent water retention capacity.

Cocopeat is widely used for containerized growing medium for the production of ornamental potter plants (Bagci et al., 2011; Scagel, 2003; Tariq et al., 2012) and other horticultural species (Ayesha et al., 2011; Erwan et al., 2013; Rubio et al., 2011; Tehranifar et al., 2007). Cocopeat is a suitable growing media with acceptable physical and chemical attributes such as $\mathrm{pH}$, electrical conductivity, bulk density and others (Abad et al., 2002).

Perlite is used in soil mixes to improve aeration and modify the soil substructure, keeping it loose, well- draining and defying compaction. Perlite is an amorphous volcanic glass that has a relatively high water content, typically formed by the hydration of obsidian. 
In horticulture, perlite can be used as a soil amendment or alone as a medium for hydroponics or for starting cuttings.

\section{Materials and Methods}

The experiment was conducted at Department of Horticulture Naini Agricultural Institute, Sam Higginbottom University of Agriculture Technology and sciences, Prayagraj. The experiment consisting of five different plants. viz, Spider plant, Screw pine, Ferns, Syngonium, Ipomea which were planted in the different media compositions viz, M0 Garden soil, $\mathrm{M}_{1}$ (Perlite + Cocopeat + Sand 1:1:1), $\mathrm{M}_{2}$ (Perlite + Cocopeat + Sand 1:1:2), $\mathrm{M}_{3}$ (Perlite + Cocopeat + Sand 1:2:1), $\mathrm{M}_{4}$ (Perlite + Cocopeat + Sand 2:1:1). The experiment was laid outdoor under Factorial completely randomized design (FCRD) replicated thrice. The findings of this experiment are being summarized as follows

\section{Results and Discussion}

\section{Increasing plant height at 180 DAP}

The data figures presented in Table 1 and Fig. 1 shows the increasing plant height in different media composition at 180 DAP varied significantly.

In vertical garden the maximum plant height was recorded at 180 days in $\mathrm{P}_{5}$ (Ipomea) $(8.2 \mathrm{~cm})$ followed by $\mathrm{P}_{4}$ (Syngonium) $(1 \mathrm{~cm})$. Whereas, the minimum plant height was recorded in $\mathrm{P}_{2}$ (Screw pine) $(0.3 \mathrm{~cm})$.

In the plant height maximum range of media was recorded at 180 days in $\mathrm{M}_{4}$ (Perlite + Cocopeat + Sand $(2: 1: 1)(3 \mathrm{~cm})$ followed by $\mathrm{M}_{2}$ (Perlite + Cocopeat + Sand 1:1:2) $(2.5 \mathrm{~cm})$. Whereas, the minimum range of media was recorded in $\mathrm{M}_{0}$ (Garden soil) $(1.2 \mathrm{~cm})$. The interaction between the plant height and media was recorded in $\mathrm{P}_{5}$ (Ipomea) and $\mathrm{M}_{2}$ (Perlite + Cocopeat + Sand 1:1:2) $(9.6 \mathrm{~cm})$.

\section{Increasing number of leaves at 180 DAP}

The data figures presented in Table 1 and Fig 2. Shows the increasing number of leaves in different media composition at 180 DAP varied significantly.

In vertical garden the maximum number of leaves was recorded at 180 days in $\mathrm{P}_{5}$ (Ipomea) (4.1) followed by $\mathrm{P}_{4}$ (Syngonium) (3.1). Whereas, minimum number of leaves was recorded in $\mathrm{P}_{2}($ Screw pine) $(0.1 \mathrm{~cm})$.

In number of leaves the maximum range of media was recorded at 180 days in $\mathrm{M}_{0}$ (Garden soil) $(2.6 \mathrm{~cm})$ followed by $\mathrm{M}_{4}($ Perlite + Cocopeat + Sand 2:1:1) (2.2cm). Whereas, the minimum range of media was recorded in $\mathrm{M}_{1}$ (Perlite + Cocopeat + Sand 1:1:1) (1.4). In the number of leaves the media was at par with $\mathrm{M}_{4}$ (Perlite + Cocopeat + Sand 2:1:1) (2.2). The interaction between the number of leaves and media was recorded in $\mathrm{P}_{4}$ (Syngonium) and $\mathrm{M}_{0}$ (Garden soil) (5.6).

\section{Increasing plant spread at 180 DAP}

The data figures presented in Table 2 and Fig. 3. Shows the increasing plant spread in different media composition at 180 DAP varied significantly.

In vertical garden the maximum plant spread was recorded at 180 days in $\mathrm{P}_{3}$ (Fern) $(909.7 \mathrm{~cm})$ followed by $\mathrm{P}_{1}$ (Spider plant) $(452.2 \mathrm{~cm})$. Whereas, minimum plant spread was recorded in $\mathrm{P}_{2}$ (Screw pine) $(354.2 \mathrm{~cm})$.

In plant spread the maximum range of media was recorded at 180 days in $\mathrm{M}_{1}$ (Perlite + Cocopeat + Sand 1:1:1) $(652.9 \mathrm{~cm})$ followed by $\mathrm{M}_{4}$ (Perlite + Cocopeat + Sand 2:1:1) $(593.2 \mathrm{~cm})$. Whereas, the minimum range of media was recorded in $\mathrm{M}_{0}$ (Garden soil) $(356.7 \mathrm{~cm})$. In the plant spread the media was at par with $\mathrm{M}_{2}$ (Perlite + Cocopeat + Sand 
1:1:2) (519.6cm), $\mathrm{M}_{4}($ Perlite + Cocopeat + Sand 2:1:1) $(593.2 \mathrm{~cm})$. The interaction between the plant spread and media was recorded in $\mathrm{P}_{3}$ (Fern) and $\mathrm{M}_{1}$ (Perlite + Cocopeat + Sand 1:1:1) $(1884.7 \mathrm{~cm})$

\section{Leaf area $\left(\mathrm{cm}^{2}\right)$}

The data figures presented in Table 2 and Fig 4. Shows the leaf area in different media composition significantly.

In vertical garden the maximum leaf area was recorded at 180 days in $\mathrm{P}_{3}$ (Fern) $\left(104.2 \mathrm{~cm}^{2}\right)$ followed by $\mathrm{P}_{2}$ (Screw pine) $\left(42.9 \mathrm{~cm}^{2}\right)$. Whereas, minimum leaf area was recorded in $\mathrm{P}_{4}$ (Syngonium) $\left(19.3 \mathrm{~cm}^{2}\right.$ ).

In leaf area the maximum range of media was recorded at 180 days in $\mathrm{M}_{1}$ (Perlite + Cocopeat + Sand 1:1:1) $\left(53.3 \mathrm{~cm}^{2}\right)$ followed by $\mathrm{M}_{2}$ (Perlite + Cocopeat + Sand 1:1:2) $\left(50.8 \mathrm{~cm}^{2}\right)$. Whereas, the minimum range of media was recorded in $\mathrm{M}_{3}$ (Perlite + Cocopeat + Sand $1: 2: 1)\left(45.2 \mathrm{~cm}^{2}\right)$. In the leaf area the media was at par with $\mathrm{M}_{4}$ (Perlite + Cocopeat + Sand 2:1:1) (49.6 $\left.\mathrm{cm}^{2}\right), \mathrm{M}_{2}$ (Perlite + Cocopeat + Sand $1: 1: 2)\left(50.8 \mathrm{~cm}^{2}\right)$. The interaction between the leaf area and media was recorded in $\mathrm{P}_{3}$ (Fern) and $\mathrm{M}_{2}$ (Perlite + Cocopeat + Sand 1:1:2) $\left(106.5 \mathrm{~cm}^{2}\right)$.

\section{Fresh vegetative mass (gm)}

The data figures presented in Table 3 and Fig 5. Shows the fresh vegetative mass in different media composition significantly.

In vertical garden the maximum fresh vegetative mass was recorded at 180 days in $\mathrm{P}_{3}$ (Fern) (119.5g) followed by $\mathrm{P}_{2}$ (Screw pine) (110g). Whereas, minimum fresh vegetative mass was recorded in $\mathrm{P}_{5}$ (Ipomwa) (75g).
In fresh vegetative mass the maximum range of media was recorded at 180 days in $\mathrm{M}_{4}($ Perlite + Cocopeat + Sand 2:1:1) (108g) followed by $\mathrm{M}_{1}$ (Perlite + Cocopeat + Sand $1: 1: 1) \quad(102.8 \mathrm{~g})$. Whereas, in the fresh vegetative mass minimum range of media was recorded in $\mathrm{M}_{3}$ (Perlite + Cocopeat + Sand $1: 2: 1)(97.6 \mathrm{~g})$. The interaction between the fresh vegetative mass and media was recorded in $\mathrm{P}_{3}$ (Fern) and $\mathrm{M}_{2}$ (Perlite + Cocopeat + Sand 1:1:2) (119.5g).

\section{Root spread (cm)}

The data figures presented in Table 3 and Fig 6. Shows the root spread in different media composition significantly.

In vertical garden the maximum root spread was recorded at 180 days in $\mathrm{P}_{3}$ (Fern) $(21.7 \mathrm{~cm})$ followed by $\mathrm{P}_{2}$ (Screw pine) $(20.4 \mathrm{~cm})$. Whereas, minimum root spread was recorded in $\mathrm{P}_{4}$ (Syngonium) $(13.9 \mathrm{~cm})$.

In root spread the maximum range of media was recorded at 180 days in $\mathrm{M}_{3}$ (Perlite + Cocopeat + Sand 1:2:1) $(20.8 \mathrm{~cm})$ followed by $\mathrm{M}_{1}$ (Perlite + Cocopeat + Sand 1:1:1) $(18.8 \mathrm{~cm})$. Whereas, in the root spread minimum range of media was recorded in $\mathrm{M}_{0}$ (Garden soil) $(18 \mathrm{~cm})$. The interaction between the root spread and media was recorded in $\mathrm{P}_{3}$ (Fern) and $\mathrm{M}_{3}$ (Perlite + Cocopeat + Sand 1:2:1) (24cm).

From the investigation conducted on different ornamental plants, it is concluded that under open conditions all plants performed well accept spider plant in M1 (Perlite +Cocopeat + Sand (1:1:1), M4 (Perlite +Cocopeat + Sand $(2: 1: 1)$. AlsoFerns and syngonium, ipomea plant growing well in M3 (Perlite +Cocopeat + Sand $(1: 2: 1)$ as well as in ${ }_{\mathrm{M} 2}$ (Perlite +Cocopeat + Sand (1:1:2). 
Table.1 Increasing plant height $(\mathrm{cm})$, increasing number of leaves in different media compositions for outdoor vertical gardening

\begin{tabular}{|c|c|c|c|c|c|c|c|c|c|c|c|c|}
\hline \multirow[t]{3}{*}{ Parameters } & \multicolumn{6}{|c|}{ Increasing plant height(cm) 180DAP } & \multicolumn{6}{|c|}{ Increasing number of leaves180 DAP } \\
\hline & \multicolumn{6}{|c|}{ Media composition } & \multicolumn{6}{|c|}{ Media composition } \\
\hline & $\mathrm{P}_{1}$ & $\mathrm{P}_{2}$ & $\mathrm{P}_{3}$ & $\mathrm{P}_{4}$ & $\mathrm{P}_{5}$ & MEAN(M) & $\mathrm{P}_{1}$ & $\mathrm{P}_{2}$ & $\mathrm{P}_{3}$ & $\mathrm{P}_{4}$ & $\mathrm{P}_{5}$ & MEAN(M) \\
\hline $\mathbf{M}_{\mathbf{0}}$ & 0.1 & 0.2 & 0.2 & 1.1 & 4.7 & 1.2 & 1 & 0 & 1.3 & 5.6 & 5 & 2.6 \\
\hline $\mathbf{M}_{2}$ & 0.6 & 0.3 & 1 & 1.2 & 9.6 & 2.5 & 1 & 0.6 & 0.3 & 1.6 & 5.1 & 1.7 \\
\hline $\mathbf{M}_{3}$ & 0.8 & 0.06 & 0.9 & 1.4 & 8.2 & 2.3 & 1 & 0 & 2 & 1.6 & 3.6 & 1.6 \\
\hline $\mathbf{M}_{4}$ & 0.1 & 0.5 & 0.4 & 0.5 & 13.7 & 3.06 & 1 & 0 & 1.6 & 4 & 4.3 & 2.2 \\
\hline \multirow[t]{2}{*}{ MEAN (P) } & 0.4 & 0.3 & 0.7 & 1 & 8.2 & & 1 & 0.1 & 1.2 & 3.1 & 4.1 & \\
\hline & F-test & C.D.at $5 \%$ & $\mathrm{SE}(\mathrm{d})$ & $\mathrm{SE}(\mathrm{m})$ & & & F-test & $\begin{array}{l}\text { C.D.at } \\
5 \%\end{array}$ & $\mathrm{SE}(\mathrm{d})$ & $\mathrm{SE}(\mathrm{m})$ & & \\
\hline Plants (P) & S & 0.4 & 0.2 & 0.1 & & & $\mathrm{~S}$ & 0.6 & 0.3 & 0.2 & & \\
\hline Media (M) & S & 0.4 & 0.2 & 0.1 & & & $\mathrm{~S}$ & 0.6 & 0.3 & 0.2 & & \\
\hline Factor $(\mathbf{P} \times \mathbf{M})$ & $\mathrm{S}$ & 1 & 0.5 & 0.3 & & & $\mathrm{~S}$ & 1.4 & 0.7 & 0.5 & & \\
\hline
\end{tabular}


Table.2 Increasing plant spread $(\mathrm{cm})$, leaf area $\left(\mathrm{cm}^{2}\right)$ in different media compositions for outdoor vertical gardening

\begin{tabular}{|c|c|c|c|c|c|c|c|c|c|c|c|c|}
\hline \multirow[t]{3}{*}{ Parameters } & \multicolumn{6}{|c|}{ Increasing plant spread $(\mathrm{cm})$ 180DAP } & \multirow{2}{*}{\multicolumn{6}{|c|}{$\begin{array}{l}\text { Leaf area }\left(\mathrm{cm}^{2}\right) 180 \text { DAP } \\
\text { Media composition }\end{array}$}} \\
\hline & \multicolumn{6}{|c|}{ Media composition } & & & & & & \\
\hline & $\mathrm{P}_{1}$ & $\mathrm{P}_{2}$ & $\mathrm{P}_{3}$ & $\mathrm{P}_{4}$ & $\mathrm{P}_{5}$ & MEAN(M) & $\mathrm{P}_{1}$ & $\mathrm{P}_{2}$ & $\mathrm{P}_{3}$ & $\mathrm{P}_{4}$ & $\mathrm{P}_{5}$ & MEAN(M) \\
\hline $\mathbf{M}_{0}$ & 548.4 & 281.3 & 398.3 & 306.7 & 249 & 356.7 & 48.5 & 49.4 & 102.1 & 25.8 & 40.5 & 53.3 \\
\hline $\mathbf{M}_{2}$ & 285.8 & 217.5 & 1332.3 & 274.6 & 488 & 519.6 & 42.5 & 40.8 & 106.5 & 16.7 & 35.2 & 48.3 \\
\hline $\mathbf{M}_{3}$ & 377.8 & 515.4 & 259.8 & 325.4 & 349.6 & 365.6 & 30.1 & 33.5 & 105.1 & 21.9 & 35.5 & 45.2 \\
\hline $\mathbf{M}_{4}$ & 671.9 & 522.6 & 673.6 & 492.9 & 605 & 593.2 & 37.2 & 45.1 & 102.8 & 16.1 & 46.9 & 49.6 \\
\hline \multirow[t]{2}{*}{ MEAN (P) } & 452.2 & 354.2 & 909.7 & 356.8 & 415.1 & & 38.8 & 42.9 & 104.2 & 19.3 & 42 & \\
\hline & F-test & C.D.at $5 \%$ & $\mathrm{SE}(\mathrm{d})$ & $\mathrm{SE}(\mathrm{m})$ & & & F-test & $\mathrm{SE}(\mathrm{d})$ & $\begin{array}{l}\text { C.D.at } \\
5 \%\end{array}$ & & & \\
\hline Plants (P) & $S$ & 165.5 & 82.1 & 58.1 & & & S & 2.1 & 4.5 & & & \\
\hline Media (M) & $S$ & 165.5 & 82.1 & 58.1 & & & $\mathrm{~S}$ & 2.1 & 4.5 & & & \\
\hline Factor (P x M) & $S$ & 370.1 & 183.7 & 129.9 & & & $\mathrm{~S}$ & 4.8 & 10 & & & \\
\hline
\end{tabular}


Table.3 Fresh vegetative mass $(\mathrm{gm})$, root spread $(\mathrm{cm})$ in different media compositions for outdoor vertical gardening

\begin{tabular}{|c|c|c|c|c|c|c|c|c|c|c|c|c|}
\hline \multirow[t]{3}{*}{ Parameters } & \multicolumn{6}{|c|}{ Fresh vegetative mass (gm) 180DAP } & \multicolumn{6}{|c|}{ Root spread (cm)180 DAP } \\
\hline & \multicolumn{6}{|c|}{ Media composition } & \multicolumn{6}{|c|}{ Media composition } \\
\hline & $\mathrm{P}_{1}$ & $\mathrm{P}_{2}$ & $\mathrm{P}_{3}$ & $\mathrm{P}_{4}$ & $\mathrm{P}_{5}$ & MEAN(M) & $\mathrm{P}_{1}$ & $\mathrm{P}_{2}$ & $\mathrm{P}_{3}$ & $\mathrm{P}_{4}$ & $\mathrm{P}_{5}$ & MEAN(M) \\
\hline $\mathbf{M}_{\mathbf{0}}$ & 106.6 & 103.3 & 117.6 & 90 & 73.3 & 98.2 & 18.6 & 19.6 & 19.6 & 13.6 & 18.6 & 18 \\
\hline $\mathbf{M}_{2}$ & 93.6 & 100.3 & 119.6 & 106 & 71.6 & 98.2 & 19 & 20.3 & 20.3 & 14.5 & 17.6 & 18.3 \\
\hline $\mathbf{M}_{3}$ & 99 & 111.3 & 121 & 81.6 & 75 & 97.6 & 23.3 & 19.6 & 24 & 16 & 21.3 & 20.8 \\
\hline $\mathbf{M}_{4}$ & 122 & 118.6 & 125.3 & 94.6 & 79.3 & 108 & 16.6 & 21 & 22.3 & 13 & 20.3 & 18.6 \\
\hline \multirow[t]{2}{*}{ MEAN (P) } & 104.7 & 110 & 119.5 & 95.5 & 75 & & 18.9 & 20.4 & 21.7 & 13.9 & 19.8 & \\
\hline & F-test & $\mathrm{SE}(\mathrm{d})$ & $\begin{array}{c}\text { C.D.at } \\
5 \%\end{array}$ & & & & F-test & $\mathrm{SE}(\mathrm{d})$ & $\begin{array}{l}\text { C.D.at } \\
5 \%\end{array}$ & & & \\
\hline Plants (P) & S & 0.7 & 1.6 & & & & $\mathrm{~S}$ & 0.3 & 0.6 & & & \\
\hline Media (M) & $S$ & 0.7 & 1.6 & & & & $\mathrm{~S}$ & 0.3 & 0.6 & & & \\
\hline Factor (P x M) & $\mathrm{S}$ & 1.7 & 3.6 & & & & $\mathrm{~S}$ & 0.7 & 1.4 & & & \\
\hline
\end{tabular}


Int.J.Curr.Microbiol.App.Sci (2020) 9(10): 2202-2216

Fig.1 Increasing plant height $(\mathrm{cm}) 180$ DAP in different media compositions for outdoor vertical gardening

16

14

12

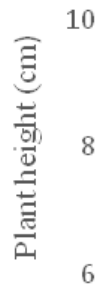

4

2

0

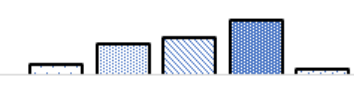

P1<smiles>[TeH][TlH]</smiles>

$\mathrm{P} 2$

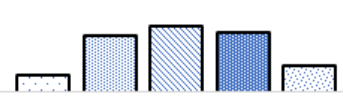

P3

Plants

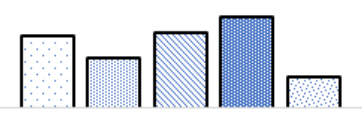

P4

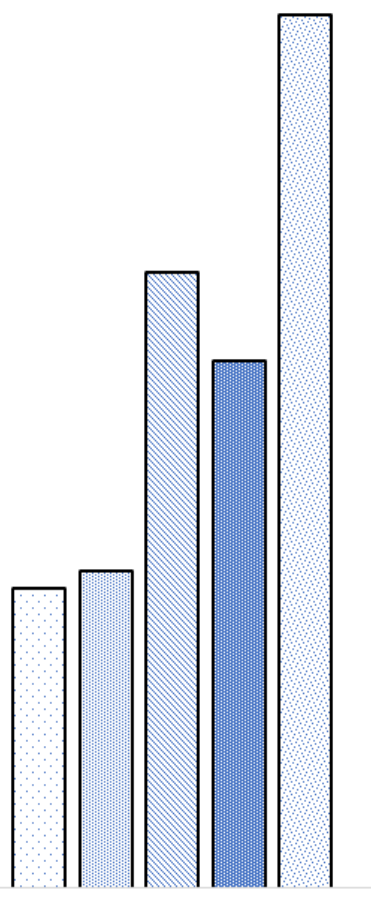

P5

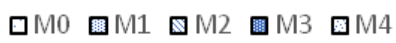


Fig.2 Increasing number of leaves 180 DAP in different media compositions for outdoor vertical gardening

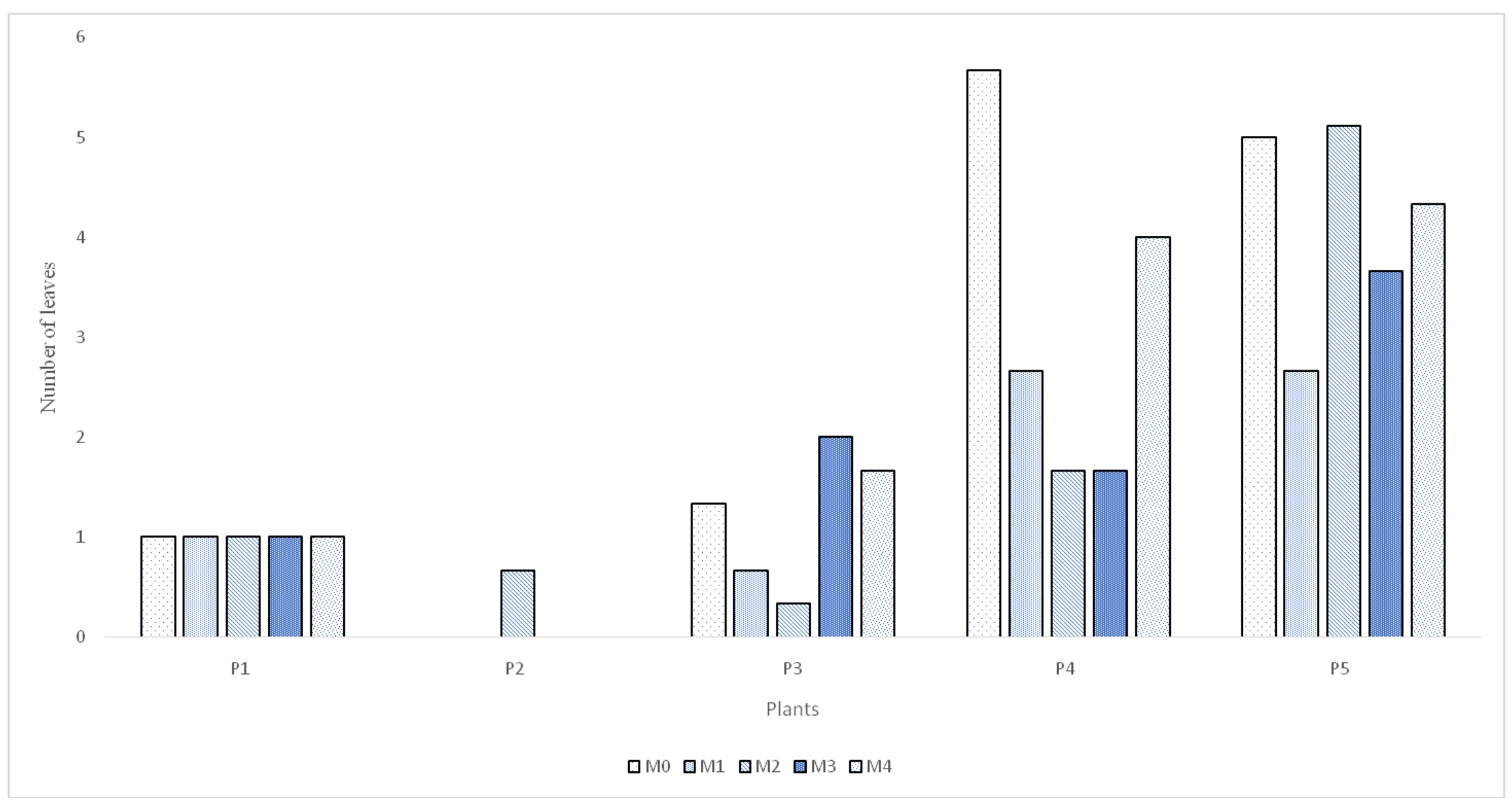


Int.J.Curr.Microbiol.App.Sci (2020) 9(10): 2202-2216

Fig.3 Increasing plant spread (cm) 180 DAP in different media compositions for outdoor vertical gardening

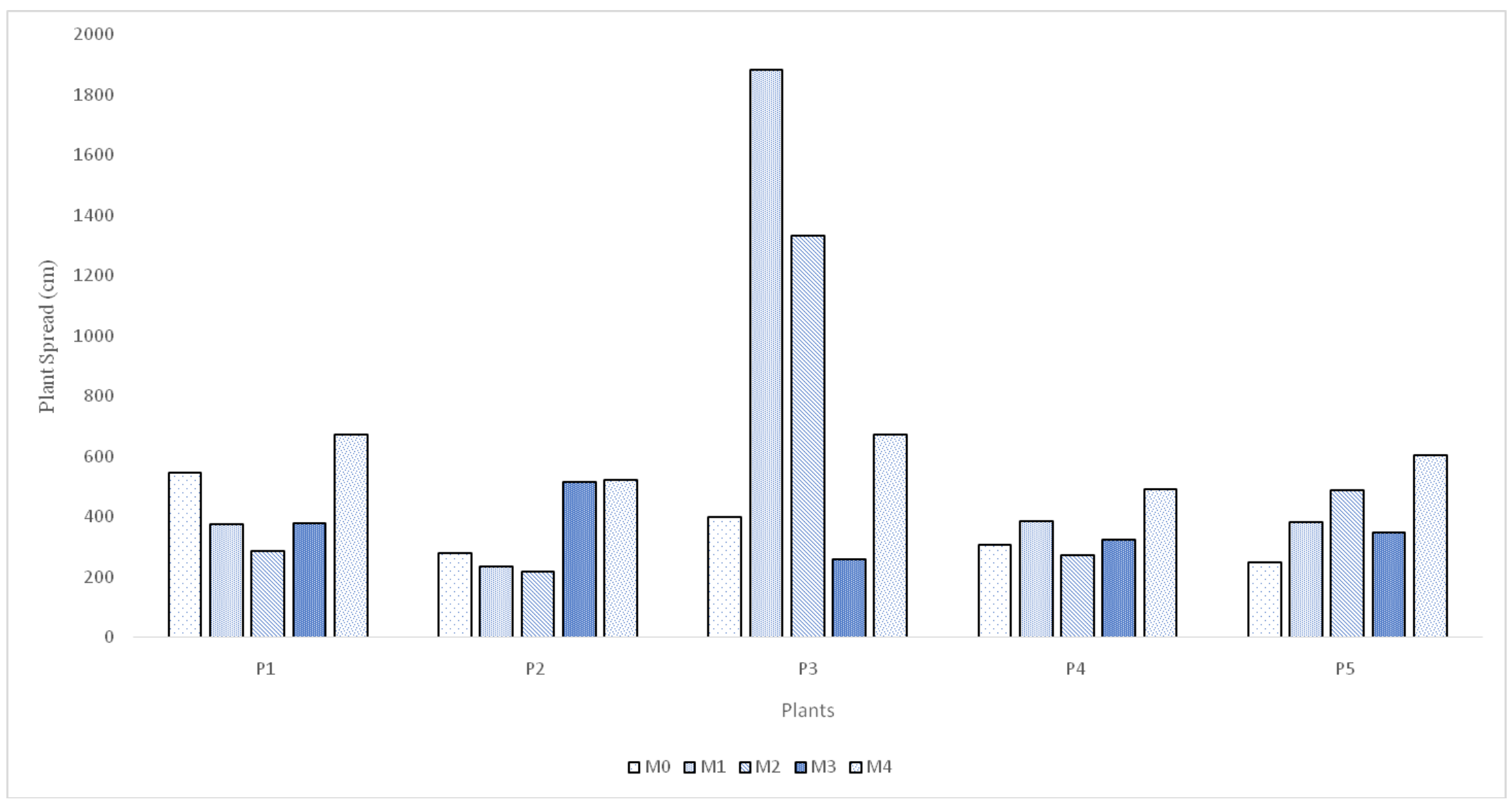


Int.J.Curr.Microbiol.App.Sci (2020) 9(10): 2202-2216

Fig.4 Leaf area $\left(\mathrm{cm}^{2}\right)$ in different media compositions for outdoor vertical gardening

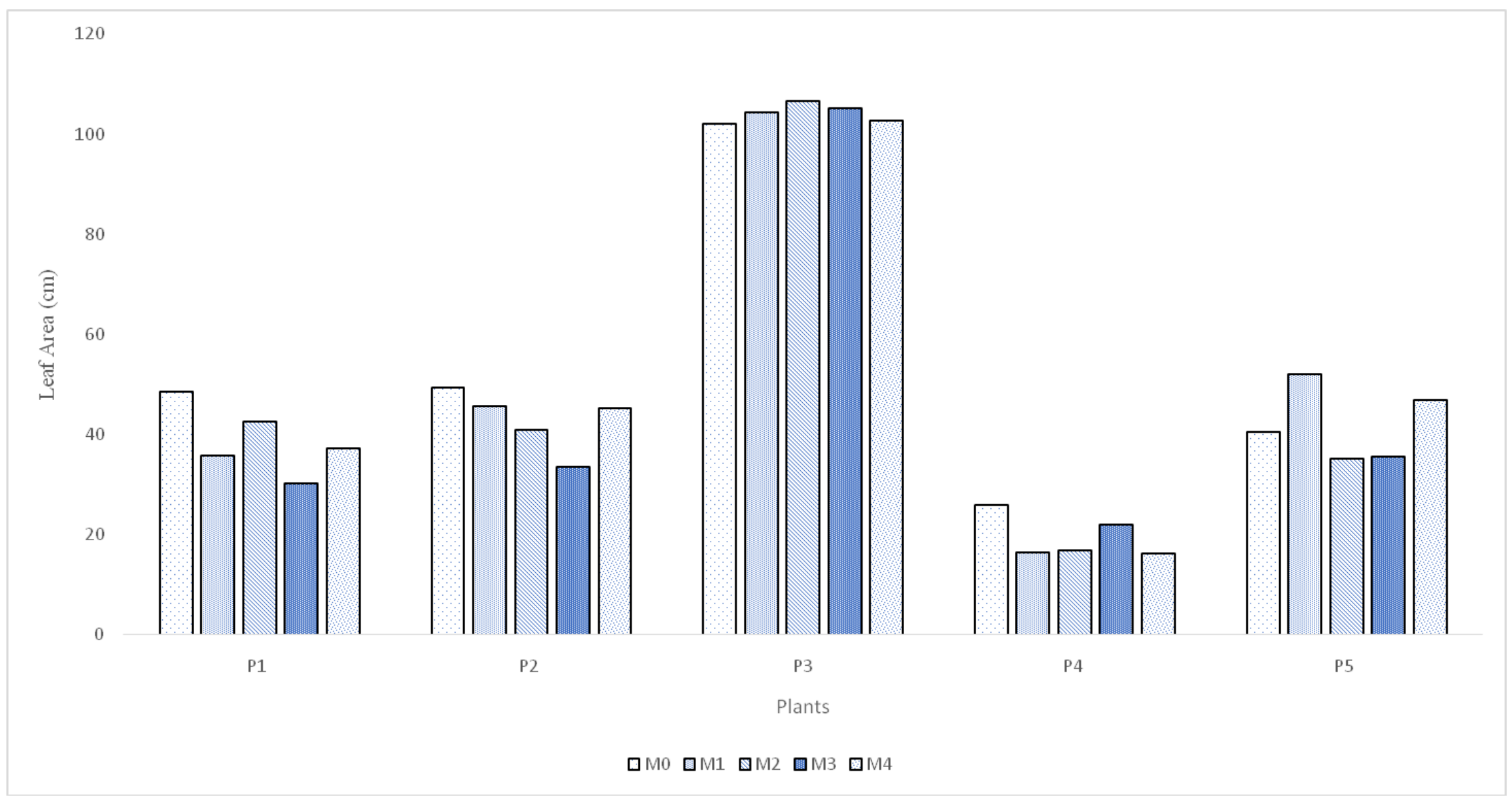


Int.J.Curr.Microbiol.App.Sci (2020) 9(10): 2202-2216

Fig.5 Fresh vegetative mass (gm) in different media compositions for outdoor vertical gardening

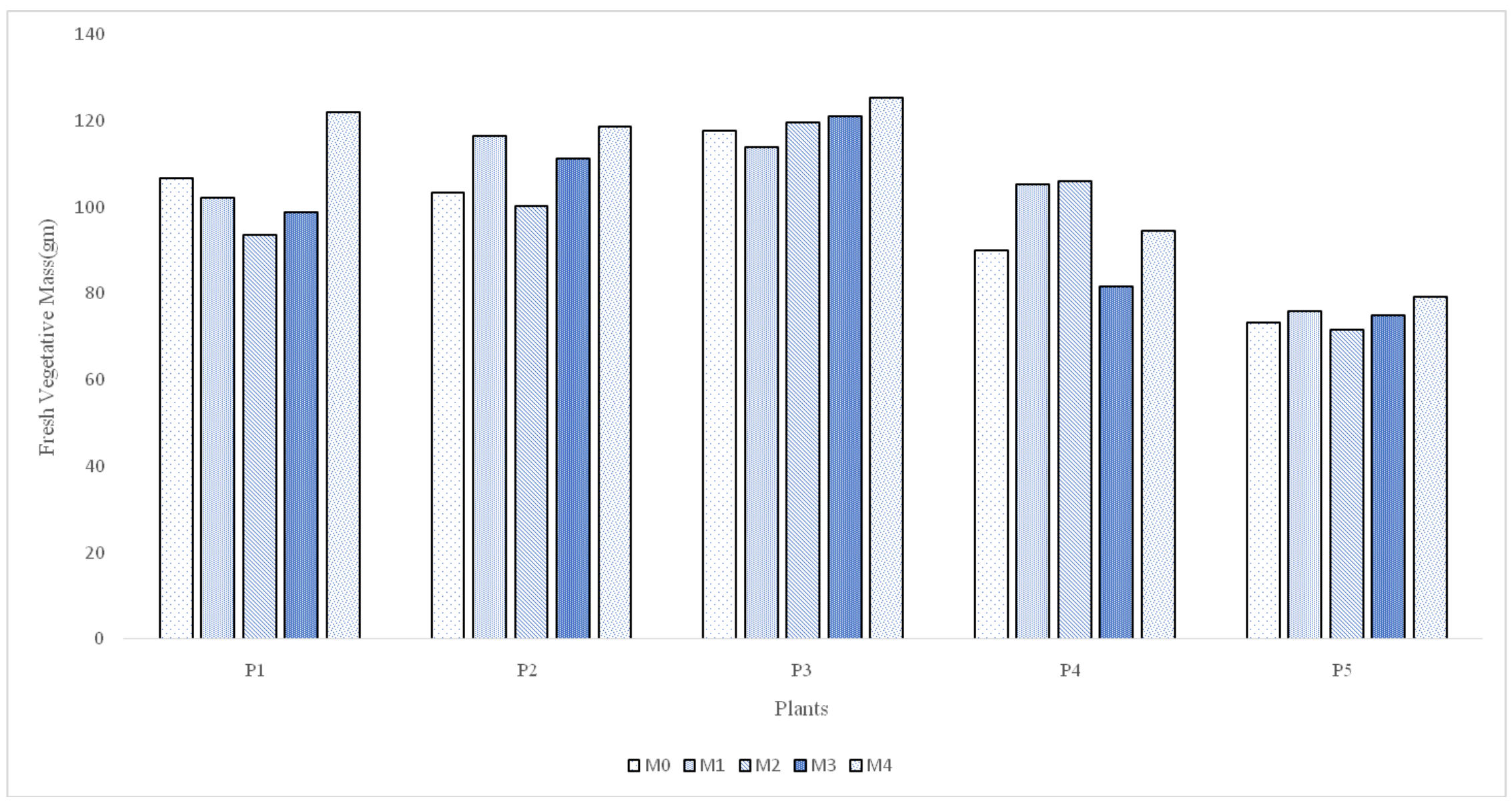


Int.J.Curr.Microbiol.App.Sci (2020) 9(10): 2202-2216

Fig.6 Root spread $(\mathrm{cm})$ in different media compositions for outdoor vertical gardening

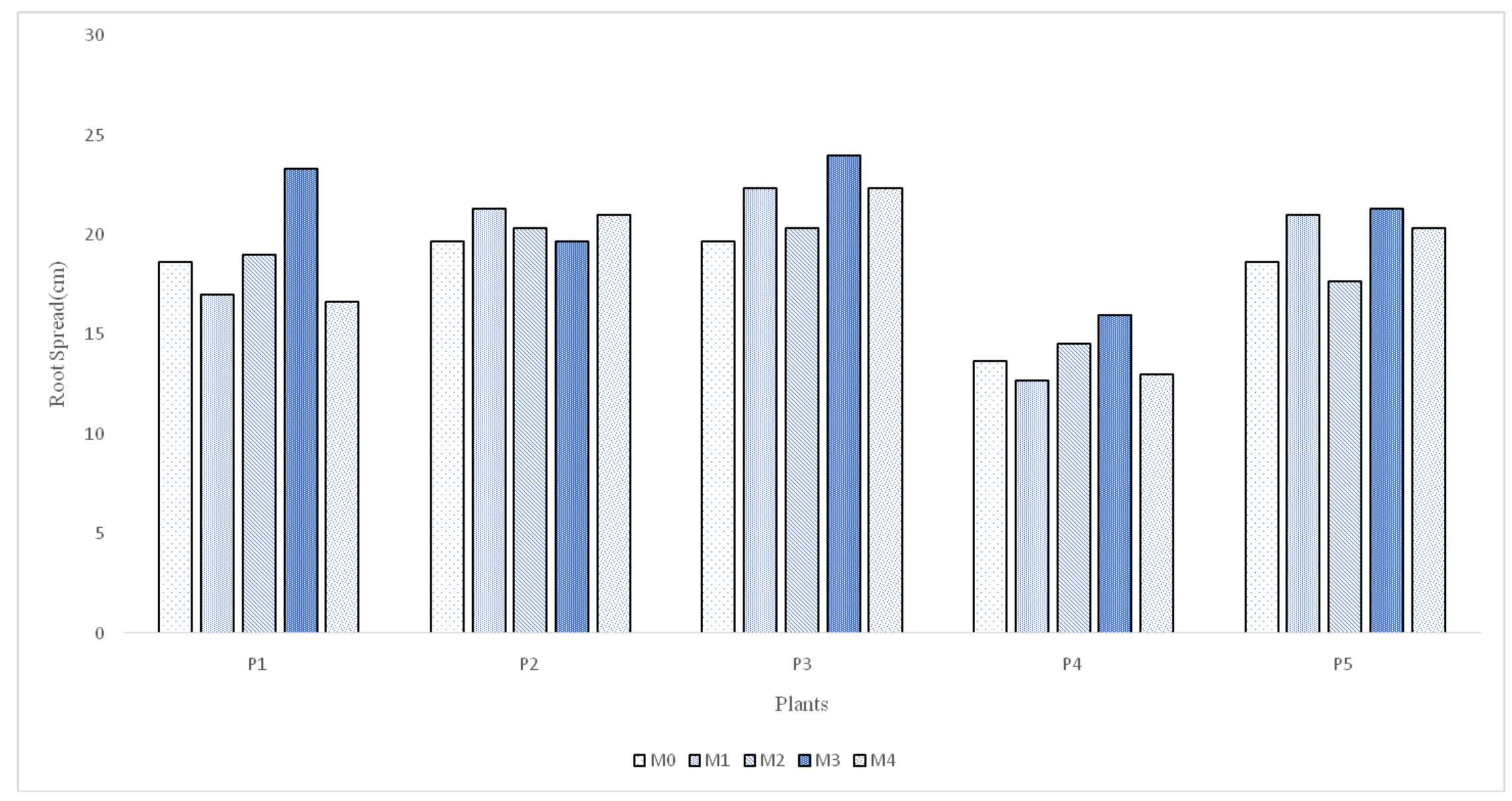




\section{References}

Ayesha, R., Fatima, N., Ruqayya, M., Qureshi, K. M. Hafiz, I.A., Khan, K.S. and Kamal, (2011) influence of different growth media on the fruit quality and reproductive growth parameters of strawberry (Fragaria ananassa). Journal of Medicinal Plants Research 5(26): 6224-6232.

Abad, M., Noguera, P., Puchades, R. Maquieira A and Noguera, V. (2002). Physicochemical and chemical properties of some coconut dust for use as a peat substitute for Containerized ornamental plants. Bioresource Technology, 82: 241-245.

Bagci, S., Cayci, G. and Kütük, C. (2011). Growth of Primula plant in coir dust and peat-based growing media. Journal of Plant Nutrition 34: 909-919.

Bergs, J. (2002), The Effect of Healthy Workplaces on the Well-being and Productivity of office Workers. International Plants for People Symposium, $1-12$.

Choi, K., W. (2013), Environmental benefits of indoor living walls. MSc (Env Mgt) Thesis, The University of Hong Kong, 2013D.

Dunnett NP, Kingsbury, N.(2004), Planting Green Roofs and Living Walls. Portland (OR): Timber Press (5):81-85

Erwan, M.R.I., Saud, H. M., Othman, R., Habib, S., Kausar, H. and Naber, L. (2013). Effect of oil palm frond compost amended coconut coir dust soilless growing media on growth and yield of cauliflower International Journal of Agriculture \& Biology15: 731-736.

Ekren, E. (2017). Advantages and risks of vertical gardens. Bartın Orman Fakültesi Dergisi, 19(1), 51-57.

Johnson, G., R. and Cartwright, C. (2005). Genotype $\mathrm{x}$ shade effects for western hemlock Canadian Journal of Forest Research35: 1496-1501

Köhler, M. (2008). "Green facades - a view back and some visions." Urban Ecosystems 11(4):423-436.

Rubio, J.S., Pereira, W.E., Garcia-Sanchez, F., Murillo, L., García, A.L. and Martinez, V. (2011), Sweet pepper production in substrate in response to salinity, nutrient solution management and training system. Horticultura Brasileira, 29(3): 275-281.

Scagel, C., F. (2003), Growth and nutrient use of ericaceous plants grown in media amended with sphagnum moss peat or coir dust. Hort Science, 38(1): 46-54.

Sharma, P. (2015). Vertical Gardens-An Innovative Element of Green Building Technology. 28(3): 300-305

Tariq, U., Rehman, S.U., Khan, M.A., Younis, A., Yaseen, M, and Ahsan, M. (2012), Agricultural and municipal waste as potting media components for the growth and flowering of Dahlia hortensis 'Figaro'. Turkish Journal of Botany36(4): 378-385.

Tehranifar, A, Selahvarzi, Y. and Alizadeh, B. (2011). Effect of different growing media on Growth and Development of Lilium (Oriental and Asiatic Hybrids) types in soiless conditions. Acta Horticulturae 900:139-142.

Waltke, B. K. (2016). Genesis: A commentary. Zondervan Academic. 11(2): 800-807.

\section{How to cite this article:}

Pattipaka Pavan Kumar, Devi Singh and Urfi Fatmi. 2020. Performance of Ornamental Plants in Different Media Compositions for Outdoor Vertical Gardening. Int.J.Curr.Microbiol.App.Sci. 9(10): 2202-2216. doi: https://doi.org/10.20546/ijcmas.2020.910.267 